\title{
The American Association for Thoracic Surgery 2016 ethics forum: Preoperative disclosure: In all honesty, my results...
}

\author{
Sandra L. Starnes, MD
}

\footnotetext{
From the Division of Thoracic Surgery, Department of Surgery, University of Cincinnati College of Medicine, Cincinnati, Ohio.

Read at the 96th Annual Meeting of The American Association for Thoracic Surgery, May 14-18, 2016, Baltimore, Maryland.

Received for publication Aug 14, 2016; revisions received Nov 11, 2016; accepted for publication Nov 16, 2016; available ahead of print Dec 10, 2016

Address for reprints: Sandra L. Starnes, MD, Division of Thoracic Surgery, Department of Surgery, University of Cincinnati College of Medicine, 231 Albert B. Sabin Way, MC 0558, Cincinnati, OH 45040 (E-mail: sandra. starnes@uc.edu).

J Thorac Cardiovasc Surg 2017;153:1209-11

$0022-5223 / \$ 36.00$

Copyright (C) 2016 by The American Association for Thoracic Surgery

http://dx.doi.org/10.1016/j.jtcvs.2016.11.035
}

You are providing information to a patient during the consent process for an esophagectomy. What is your obligation to recite your personal experience and results with this procedure? What if you perform 60 esophagectomies per year? What if you perform only 5 esophagectomies per year and there is a high-volume center 10 miles away?

Clinical outcomes for hospitals, practices, and individual physicians are increasingly coming under scrutiny. Cardiothoracic surgery has been at the forefront of this with public reporting of hospital and individual surgeon performance data in several states.

Controversy certainly surrounds reporting of performance data, but what about the surgeon's responsibility to disclose his or her results to patients? Disclosure of personal performance data is really an issue of informed consent, specifically how much information is needed for a truly informed decision.

\section{LEGAL REQUIREMENT}

The necessity of even obtaining patient consent is highlighted in Schloendorff $v$ The Society of the New York Hospital $^{1}$ in the early 1900 s, in which a patient consented to an examination under anesthesia. With the patient under anesthesia, the surgeon removed a tumor, a procedure for which she did not consent. In his famous ruling, Justice Benjamin Cardozo states that "every human being...has a right to determine what shall be done with his own body; and a surgeon who performs an operation without his patient's consent, commits an assault for which he is liable in damages." ${ }^{1}$ Over the next several decades, consent evolved into informed consent; the key elements in most states are a description of the nature and purpose of the procedure, benefits of the procedure, reasonably known risks, and alternatives. How much and what specific information must be disclosed are not well defined, and the standard of informed consent varies by state. The professional standard, the earliest model, relies on what most physicians would disclose in a similar situation. The reasonable patient

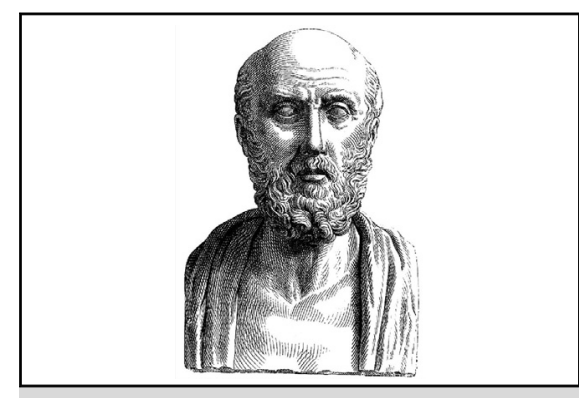

"Life is short, and the Art long; experience fallacious, and judgment difficult."-Hippocrates

\section{Central Message}

Respect for patient autonomy requires having an honest discussion of the risks, benefits, and alternatives to the treatment we propose. Honesty about our personal experience and outcomes is paramount.

See Editorial Commentary page 1212.

standard is based on what a reasonable patient would want to know under similar circumstances. The subjective standard is defined by what a specific patient would want to know on the basis of their individual values and goals. There are obvious shortcomings of each of these standards. Childers and colleagues ${ }^{2}$ proposed a balanced model between the reasonable patient and the subjective model. For example, when discussing the risks and benefits of a higher-risk procedure in an older patient whose primary concern is maintaining independence, a surgeon should include a discussion about the need for discharge to a nursing home. This model improves patient autonomy in making informed choices and can enhance the physicianpatient relationship without being overly burdensome.

Although a large number of cases surround the legal issues of informed consent, few cases address the legal requirements of disclosing personal performance data and those that do often reach conflicting conclusions. Whiteside $v$ Lukson $^{3}$ involved a case of a bile duct injury during a surgeon's first few laparoscopic cholecystectomies. The fact that the surgeon had done only a few of these procedures was not disclosed to the patient. The Court of Appeals of Washington ruled that the surgeon had no duty to disclose his inexperience with the procedure. The Court further warned that broadening disclosure requirements could lead to a slippery slope in which even a physician's medical school grades or financial situation could be considered 
TABLE 1. Benefits and risks of disclosure of individual performance data during informed consent

\begin{tabular}{ll}
\hline \multicolumn{1}{c}{ Benefits } & \multicolumn{1}{c}{ Risks } \\
\hline Enhanced patient autonomy & Inaccuracy of data \\
Improved decision making & Increased anxiety about surgery \\
Enhanced physician-patient trust & $\begin{array}{c}\text { Compromised physician-patient } \\
\text { trust }\end{array}$ \\
\hline
\end{tabular}

material under the reasonable patient standard. In Johnson $v$ Kokemoor ${ }^{4}$ the Supreme Court of Wisconsin ruled that a physician did have the duty to disclose individual experience. In this case, a surgeon performed a complex aneurysm clipping for which he had little experience, resulting in partial paralysis. The Court ruled that the surgeon should have provided the patient the extent of his experience, compared the mortality and morbidity rates of experienced versus inexperienced surgeons, and offered referral to a more experienced center. They further stated that this ruling was specific to this case in which there is a vast body of literature regarding the impact of experience on outcomes. ${ }^{4}$

\section{ETHICAL OBLIGATION}

No clear legal standard addresses the issue of disclosure of personal performance data. Let's now look at the ethics of disclosure of personal performance data. The risks and benefits of disclosure are outlined by Burger and colleagues ${ }^{5}$ and are summarized in Table 1.

\section{Benefits of Disclosure}

The benefits of disclosure focus on respect for patient autonomy, one of the fundamental principles of bioethics. Respect for autonomy is not only allowing patients to make their own decisions about treatment but also ensuring that they are making truly informed decisions. In many cases, individual surgeon performance data are a factor in the risk of a particular procedure. Using the reasonable patient standard, one can assume that a reasonable patient would want to know this information. Schneider and Epstein $^{6}$ explored the question of whether patients want performance data. They surveyed 474 patients who had undergone a coronary artery bypass operation in Pennsylvania. Only $12 \%$ of patients knew of the Consumer Guide, which reports the risk-adjusted mortality of all cardiac surgeons and hospitals in the state, before their surgery. Less than $2 \%$ of patients were aware of their specific surgeon's results and less than $1 \%$ said that the surgeon rating had a significant influence on their decision. However, after patients were told of the Consumer Guide, $55 \%$ were very/somewhat interested in the information and $58 \%$ of patients would definitely/probably change surgeons if their surgeon's mortality rates were higher than expected. It is interesting that these numbers aren't higher, and I wonder if they would be if the survey was taken before their operation.

\section{Risks of Disclosure}

One of the main risks of disclosure relates to availability and accuracy of individual performance data. Not all surgeons have access to their individual data, especially risk-adjusted data. If a surgeon does have access to their data, what is the reliability of these data? Who is collecting the data is certainly a large factor. The quality of the data abstraction is a critical factor in the accuracy of the data. Although there is a conflict of interest against surgeons collecting their own data, surgeons should have some oversight of the process to ensure that the data collection is accurate. The database that the individual or hospital is using also is a factor. Risk-adjusted comparisons are the gold standard; however, risk-adjusted models are far from perfect. Sample size for less common procedures is limited, and including every factor that might be important is impossible. Many databases include only a fraction of cases. The dataset that a surgeon uses to compare his/her results against is important. Mortality rates in the Society of Thoracic Surgeons (STS) general thoracic database are generally lower than in broader databases. For example, a surgeon with a postoperative esophagectomy mortality rate of $6 \%$ compares favorably with national data using the Nationwide Inpatient Sample (reported mortality 6.1\%); however, this is approximately twice the mortality rate using the STS database (reported mortality 3.1\%). ${ }^{7}$ The impact of performance data on junior surgeons also is a consideration because it takes several years to establish enough of a volume for fair comparison. This is also true of uncommon procedures, in which outcomes among small sample sizes are meaningless. Robert $\mathrm{Sade}^{8}$ summarizes this concept in a case commentary involving informed consent for a percutaneous valve trial: "This complication rate alone says nothing about (the surgeon's) competence... or the benefits of percutaneous valve replacement, so to provide (the patient) with the (surgeon's results) would be misleading at best, and could lead to a poorly informed - and therefore unwarranted - decision...." Although respect for patient autonomy by providing important and accurate information is critical, supplying inaccurate and flawed information is a disservice and potentially harmful to our patients. Although having accurate and relevant information is critical, it is also equally important to be able to convey the information in a way that is clear and understandable to our patients. While this can be challenging, a particular patient's risk is often best explained relative to the average. Asking patients to summarize their understanding of the potential risks is one way of confirming comprehension.

A recent article highlights the inconsistencies seen among different databases. Allen and colleagues ${ }^{9}$ compared the results of the American College of Surgeons National Surgical Quality Improvement Program (NSQIP) and the STS databases for general thoracic surgical procedures in a single year at a single institution. A common database 
abstractor was used for both databases. The NSQIP database captured $19 \%$ of the cases, whereas the STS database captured $100 \%$ of cases. The overall mortality rate was the same $(1.6 \%$ vs $1.6 \%)$. However, the overall morbidity was higher in the STS database $(30.3 \%$ vs $17.2 \%)$. The operative mortality for esophageal resections was significantly higher in the NSQIP database $(10.3 \%$ vs $3 \%$ ). By using the NSQIP data, the institution was in the bottom eighth decile for mortality. However, when using the STS data, the mortality was better than the national average $(1.2 \%$ vs $1.7 \%)$.

If we agree that performance data should be shared with patients, the next question is who should disclose the results. Should it be the surgeon? That certainly introduces surgeon bias. Would poorly performing surgeons disclose their results? Finally, how much and what data should be disclosed? Should we disclose only overall mortality, procedure-specific mortality, specific morbidities, or long-term outcomes such as cancer-specific survival? Too much data can overwhelm patients.

\section{Introducing a New Procedure}

Innovation is important in medicine and particularly cardiothoracic surgery. How do we ethically introduce new procedures into our practice, such as robotic lobectomy? The benefits of these new procedures may be unknown, there may be unforeseen risks, and the learning curve may be associated with higher risk than a standard procedure.

Char and colleagues ${ }^{10}$ conducted a survey of patients and surgeons regarding informed consent for laparoscopic/robotic versus standard hepatectomy. The most important factors to both patients and surgeons included a clear statement that the procedure is new, information regarding the surgeon's experience, known risks, and potential unknown risks. Other important factors that a surgeon should explain include the specific training he/she underwent for the new procedure, the use of expert assistance such as another surgeon who has experience with the new procedure, and his/ her experience with similar procedures (I haven't done this particular procedure thoracoscopically; however, I've done hundreds of similar procedures open and hundreds of other procedures thoracoscopically). Patients are typically willing to undergo a new procedure when they have a clear understanding of the potential benefits and risks, and what the surgeon has done to mitigate the risks.

\section{CONCLUSIONS}

No clear legal requirement mandates disclosure of personal results as part of the informed consent process. Ethically, however, disclosure entails risks and benefits. Respect for patient autonomy requires that we have an honest discussion of the risks, benefits, and alternatives to the treatment we propose. Honesty about our personal experience and outcomes is paramount. This requires that we know what our true outcomes are and continually seek to improve. There will almost always be someone with more experience or better outcomes; therefore, referral to the most experienced surgeon is not feasible in most situations. However, every surgeon should have the courage and humility to honestly assess their own abilities and realize when referral to another surgeon is truly in the patient's best interest.

\section{Conflict of Interest Statement}

Author has nothing to disclose with regard to commercial support.

\section{References}

1. Schloendorff $v$ The Society of the New York Hospital. Court of Appeals of New York, 105 N.E. 92 (1914).

2. Childers R, Lipsett PA, Pawlik TM. Informed consent and the surgeon. J Am Coll Surg. 2009;208:627-34.

3. Whiteside v Lukson. Court of Appeals of Washington, 947 P.2d 1263 (1997).

4. Johnson v Kokemoor. Supreme Court of Wisconsin, 545 N.W.2d 495 (1996).

5. Burger I, Schill K, Goodman S. Disclosure of individual surgeon's performance rates during informed consent: ethical and epistemological considerations. Ann Surg. 2007;245:507-13.

6. Schneider EC, Epstein AM. Use of public performance reports: a survey of patients undergoing cardiac surgery. JAMA. 1998;279:1638-42.

7. LePar DJ, Bhamidipati CM, Lau CL, Jones DR, Kozower BD. The Society of Thoracic Surgeons General Thoracic Database: establishing generalizability to national lung cancer resection outcomes. Ann Thorac Surg. 2012;94:216-21.

8. Sade RM. Technical skill and informed consent. Virtual Mentor. 2010;12:87-90.

9. Allen MS, Blackmon S, Nichols FC, Cassivi SD, Shen KR, Wigle DA Comparison of two national databases for general thoracic surgery. Ann Thorac Surg. 2015;100:1155-61.

10. Lee Char SJ, Hills NK, Lo B, Kirkwood KS. Informed consent for innovative surgery: a survey of patients and surgeons. Surgery. 2013;153:473-80. 